\title{
Severe acute cholecystitis (Tokyo III) in high risk patients: Should cholecystectomy be preferred over percutaneous drainage?
}

\section{David Venegas}

Universidad del Rosario

Carlos Rey ( $\nabla$ carlosrey991@gmail.com )

Pontificia Universidad Javeriana

\section{Felipe Girón}

Universidad del Rosario

\section{David Peña}

Universidad del Rosario

\section{Lina Rodriguez}

Universidad de Los Andes

\section{Marco Vanegas}

Universidad del Rosario

\section{Sebastian Puello}

Universidad del Rosario

\section{Barbara Rodriguez}

Universidad del Rosario

\section{Susana Rojas}

Hospital Universitario Méderi

\section{Danny Conde}

Hospital Universitario Méderi

\section{Research Article}

Keywords: Cholelithiasis, Acute Cholecystitis, Cholecystectomy, Cholecystostomy, Outcomes, Gallstones.

Posted Date: October 4th, 2022

DOI: https://doi.org/10.21203/rs.3.rs-1351447/v2

License: (c) (i) This work is licensed under a Creative Commons Attribution 4.0 International License.

Read Full License 


\section{Abstract}

\section{Background}

Current guidelines advise the use of less aggressive procedures for the solution of cholecystitis in high risk patients. However, recent literature has shown better results in those patients managed with laparoscopic cholecystectomy. We aim to describe outcomes in high-risk patients with severe acute cholecystitis (Tokyo III) according to 2018 guidelines.

\section{Methods}

Patients that underwent laparoscopic cholecystectomy and percutaneous drainage by cholecystostomy between January 2018 and January 2020 were included in descriptive analysis. Bivariate analysis of Tokyo III patients was performed between variables involved.

\section{Results}

A total of 622 patients were included. $54.66 \%$ of patients were female. The mean age was $66.6 \pm 16.52$ years. 288 patients were classified as grade III in Tokyo classification, 28.98\% underwent cholecystostomy and $71.02 \%$ cholecystectomy. Mortality and complication rate had no significant differences between the groups ( $p=0.09-p=0.1$ respectively). The in-hospital length of stay was significantly higher in patients that required cholecystostomy with a mean of 15.43 days versus 9.97 days in the LC group, with a statistically significant difference (p $0.000 \mathrm{Cl} 95 \%)$.

\section{Conclusions}

Laparoscopic cholecystectomy seems to be a feasible treatment choice over percutaneous cholecystostomy in terms of mortality, reintervention and in-hospital stay length.

\section{Background}

Gallstones are the most common cause of acute cholecystitis (AC) [1], nevertheless $80 \%$ of the patients with gallstones could be asymptomatic and $1-3 \%$ of patients with symptomatic disease develop AC [1, 2]. According to Shaffer et al almost $10-15 \%$ of the American population have or will have AC [3].

Following the 2018 Tokyo guidelines AC severity is classified based on the clinical status of the patient [4]. Patients with mild illness do not develop any organ failure and should undergo early laparoscopic cholecystectomy (LC) combined with antibiotic regimen; those with moderate disease require urgent/early or delayed/elective LC depending on the success of the general supportive treatment, and in patients with severe disease (with any organ failure) and limited performance status biliary drainage is required [4]. However in patients with improved functional status, surgery it's a feasible treatment choice [4]. For that reason In young, healthy patients with no comorbidities, laparoscopic cholecystectomy (LC) it's the gold standard treatment for gallstone related acute cholecystitis [5]. However, it's still a matter of concern the 
surgical management of patients with severe disease, high risk such as elderly, with increased operative risk due to comorbidities [6], also in patients with negative predictive factors such as jaundice, respiratory or neurological dysfunction, as well limited functional reserves could impact in clinical postoperative outcomes, and increase morbidity and mortality risk and laparoscopic cholecystectomy should be delayed $[4,6,7]$. For that reason, minimally invasive techniques such as percutaneous drainage of the gallbladder are described in the management of these patients, avoiding surgical risk, offering a temporary solution, being the preferred management based on some international guidelines $[4,8]$. Nonetheless, percutaneous cholecystostomy (PC) isn't a definitive treatment, and could lead to readmissions, recurrent cholecystitis, and increased risk of biliary complications [9-12]. Nowadays, a recent randomized clinical trial support the possibility to perform surgical approach in high risk patients in selected population [6], with clinical impact and in financial burden, however, some studies report an increased morbidity of $41 \%$ and $5 \%$ rate or mortality in emergency LC in high risk patients $[13,14]$.

These data show that the management of $A C$ with severe disease and in high risk patients remains to be a matter of debate. This study aims to describe the population of patients that enter the emergency room with AC, and shows the clinical outcomes of patients with Tokyo III grade of cholecystitis who underwent cholecystectomy or cholecystostomy according to international guidelines.

\section{Methods}

\section{Data Management}

With the Institutional (Hospital Universitario Mayor Méderi) Review Board's approval and following Health Insurance Portability and Accountability Act (HIPAA) guidelines, a retrospective review of a prospectively collected database was conducted. All patients over 18 years of age who underwent laparoscopic/open cholecystectomy and percutaneous drainage by cholecystostomy between January 2018 and January 2020 were included. For high risk analysis we include patients with severe disease (According to Tokyo III classification) associated with American Anesthesiologist Association (ASA) greater than 3. Patients with no surgical description and missing data were excluded.

\section{Follow-up}

Preoperative data included patient demographics, serum laboratories, imaging diagnostic approach, as well, Tokyo classification recalculated based on the clinical and laboratory characteristics. Operative approach by cholecystectomy (open or laparoscopic), and drainage by cholecystostomy (percutaneous or laparoscopic), 30 days morbidity and mortality, and follow-up. In-hospital postoperative complications were assessed and classified using clavien-dindo. Interval cholecystectomy was performed after 8 weeks of percutaneous management.

\section{Statistical analysis}


Descriptive statistics were reported in terms of variable nature. Qualitative analysis was performed in terms of frequencies and percentages, while quantitative analysis was done in terms of mean and standard deviations of normally distributed data and medians and interquartile ranges (IQRs) for nonnormally distributed data. Bivariate analysis was performed. Qualitative variables were analyzed using chi-square statistics (Fisher's exact test when appropriate). Quantitative variables were analyzed, according to Kurtosis/Skewness test with Spearman's or Pearson's association's correlation coefficients when appropriate. Bivariate analysis between qualitative and quantitative variables was performed using the Mann-Whitney test or the t-test. Odds ratios with $95 \%$ confidence intervals were provided when appropriate. Multinomial logistic regression was performed between the approach and clinical outcomes such as mortality, re-intervention, and any complication. T-test was performed between approach and overall, in-hospital stay. P-value $<0.05$ were defined as statistically significant.

\section{Results}

Preoperative characteristics. A total of 622 patients were included. $54.66 \%$ of patients were female. The mean age was $66.6 \pm 16.52$ years. The mean body mass index (BMI) was $26.49 \pm 5.15 \mathrm{Kg} / \mathrm{m} 2$. Obesity history was present in $23 \%$ of the cases. (Table 1 ). Serum laboratory tests were analyzed, the mean white blood cell count was $12.909 \pm 6.206$, neutrophil's mean was $11.981 \pm 2.811$. Arterial gasometry was performed as well, mean PaFi was $263.9 \pm 49.00$, other laboratory results are summarized in Table 2 . Tokyo classification was revised, and re-classified based on clinical history, summarized in Table 3 . In $98.39 \%$ of the cases imaging techniques were used for the diagnosis, in the majority of the cases $(80.86 \%)$ ultrasonography was preferred. Cholangio-Resonance was used in $22.03 \%$ of patients who have a risk of choledocholithiasis. 
Table 1

Demographics

\begin{tabular}{|ll|}
\hline Variable & Result \\
\hline Age & $66.6(16.52)$ \\
\hline Gender \% (n) & \\
\hline Male & $45.3(282)$ \\
\hline Female & $54.6(340)$ \\
\hline Height & $1,63(6,3)$ \\
\hline Weight & $69,3(14,09)$ \\
\hline Body mass Index & $26,49(5,15)$ \\
\hline Obesity \% (n) & \\
\hline Yes & $23(132)$ \\
\hline No & $77(442)$ \\
\hline Clinical Cholecystitis \% (n) & \\
\hline Yes & $81,6(508)$ \\
\hline No & $18,3(114)$ \\
\hline
\end{tabular}

Table 2

Laboratory test

\begin{tabular}{|ll|}
\hline Variable & Result \\
\hline White Blood Cell Count & $12.909(6.202)$ \\
\hline Neutrophils & $11.981(2.811)$ \\
\hline Platelet Count & $260.000(166.334)$ \\
\hline PaFi & $263.91(49)$ \\
\hline Creatinine & $4.59(83.49)$ \\
\hline INR & $1.32(0.43)$ \\
\hline
\end{tabular}


Table 3

Tokyo Clasification

\begin{tabular}{|cll|}
\hline & Clinical History & Revised Clasification \\
\hline Tokyo I & $18(58)$ & $25.8(161)$ \\
\hline Tokyo II & $44(142)$ & $27.8(173)$ \\
\hline Tokyo III & $37(122)$ & $46.3(288)$ \\
\hline
\end{tabular}

\section{Operative characteristics.}

Cholecystectomy was performed in $83.79 \%$ of the patients. laparoscopic cholecystectomy was performed in $79 \%$ of the cases, an open approach was preferred in $3.05 \%$ of the cases. In $1.13 \%$ of the cases, subtotal cholecystectomy was performed due to several inflammatory processes. Percutaneous drainage by cholecystostomy was performed in $13.50 \%$ of the patients, and in $1.61 \%$ drainage was made during the laparoscopy approach. The conversion rate to open surgery was $7.23 \%$. The hospital overall stay mean was $9.75 \pm 9.11$ days.

\section{Complications and follow-up.}

Mortality was observed in $3.38 \%$ of the cases. The Re-intervention rate was $4.66 \%$. Overall complications after 30 -day follow-up were observed in $5.95 \%$ of the patients. Bile duct injury after cholecystectomy was present in $0.16 \%$. Summarized data are in Table 4. 
Table 4

Complications

\begin{tabular}{|ll|}
\hline Variable & Result \\
\hline Mortality & $3.38(21)$ \\
\hline Re-intervention & $4.56(29)$ \\
\hline Surgical Site infection & \\
\hline Superficial & $0.8(5)$ \\
\hline Organ-space & $1.7(11)$ \\
\hline Postoperative ileus & $0.96(6)$ \\
\hline Bile duct injury & $0.16(1)$ \\
\hline Evisceration & $0.8(5)$ \\
\hline Open Abdomen & $0.81(5)$ \\
\hline Bile leakage & $0.48(3)$ \\
\hline Organ Failure & $0.32(2)$ \\
\hline Bleeding & $0.32(2)$ \\
\hline Ventilatory Failure & $0.48(3)$ \\
\hline Pulmonary Embolism & $0.48(3)$ \\
\hline Clavien Dindo & \\
\hline 0 & $92.59(575)$ \\
\hline 1 & $0.81(5)$ \\
\hline 2 & $0.48(3)$ \\
\hline 3 & $2.74(17)$ \\
\hline 4 & $0.16(1)$ \\
\hline 5 & $3.22(20)$ \\
\hline
\end{tabular}

\section{Tokyo III Cholecystectomy versus Cholecystostomy.}

A total of 288 patients were re-classified with Tokyo III cholecystitis, of those, $28.98 \%$ underwent cholecystostomy and $71.02 \%$ cholecystectomy. In cases of drainage, mortality was observed in 8 patients, compared with 9 patients in the cholecystectomy group. In terms of re-intervention, 11 patients with cholecystostomy required surgical re-operation, just 7 patients that underwent LC required reintervention. In overall complications, there are no differences between the groups, 12 patients of each one present at least one complication. The in-hospital length of stay was significantly higher in patients 
that require cholecystostomy with a mean of 15.43 days versus 9.97 days in the LC group. Statistical analysis was performed. Patients that underwent cholecystostomy during a Tokyo III episode of cholecystitis, are more likely to require surgical re-intervention, with a 4.29 Relative Risk, with statistical significant value (p.004 Cl 95\%). In-hospital stay, have significant differences comparing patients that underwent cholecystectomy or cholecystostomy (mean of 9.97 days versus 15.43 days), with a statistical value of $p=0.000(\mathrm{Cl} 95 \%)$. In terms of mortality rate, there is no statistical relationship between cholecystostomy/cholecystectomy in patients with Tokyo III grade $(p=0.09)$. Complication's rate do not show any significant relationship between LC or PC. (p $0.1 \mathrm{Cl} 95 \%$ ). (See Table 5) 2

Table 5

Statistical Analysis.

\begin{tabular}{|llll|}
\hline Variable & LC & PC & P value \\
\hline Re-intervention & $2.47 \%$ & $3.88 \%$ & $0.004(\mathbf{0 . 0 0 2 - 0 . 0 5 )}$ \\
\hline Overall Complication & $4.24 \%$ & $4.24 \%$ & $0.1(0.08-0.5)$ \\
\hline Mortality & $3.11 \%$ & $2.82 \%$ & $0.09(0.85-0.25)$ \\
\hline Bile duct injury & $0.16 \%$ & $0 \%$ & $0.12(0.1-0.9)$ \\
\hline In hospital Stay* & $9.97 d$ & $15.43 d$ & $0.000(0.000-0.001)$ \\
\hline In-hospital stay: Mean. ${ }^{*}$ & & \\
\hline
\end{tabular}

\section{Discussion}

AC surgical management constitutes the gold standard in all severity levels, nevertheless, in patients with severe disease and considered as high risk such as elderly, with increased operative risk due to comorbidities other management approaches are considered including percutaneous drainage of the gallbladder [6]. Other approaches different to LC do not offer definitive treatment and could lead to readmissions, recurrent cholecystitis, and increased risk of biliary complications [9-12]. Tokyo guidelines 2018 established ASA-PS and negative predictive factors (Jaundice, respiratory and neurological dysfunction) in order to consider whether or not PC, recommending percutaneous cholecystostomy and supportive treatment in case of severe AC in high surgical risk patients. [4]

Few recent studies have compared both techniques (LC versus PC). Garcés-Albir et al showed in 461 patients from 2005 to 2016 an increased mortality risk, higher readmission and complications in patients that underwent PC [12]. Only one randomized clinical trial has been published up to date, The CHOCOLATE trial, showing clear advantages towards EC in terms not only on clinical outcomes but also in economical considerations [6].

The CHOCOLATE trial [6] as mentioned before, is the only randomized clinical trial that analyzes the clinical outcomes of patients treated with PC or LC for high risk patients with AC. In terms of mortality rate, in our study $3.11 \%(n=9)$ of patients that underwent LC died versus $2.82 \%(n=8)$ of patients that 
follow PC, with no statistical differences ( $\mathrm{p}$ value $=0.09 \mathrm{Cl} 95 \%$ ); comparable results with the ones obtained by Loozen et al. [6].

Another clinical outcome, frequently analyzed in the literature, it's the requirement of surgical complications and need of re-intervention. In our population, $2.47 \%$ of patients that were treated with LC versus $3.88 \%$ of the cases in patients that underwent $P C$ required reintervention, in this case with significant statistical relationship. $(p=0.004 \mathrm{Cl} 95 \%)$, and with a 4.92 increased risk-fold to require surgical revision, our data it's similar to the one reported in the CHOCOLATE trial [6].

It's well known, according to Törnqvist et al [15] that patients with acute cholecystitis, inflammatory process and severe disease have twice the risk of bile duct injury[15], however our results shows that in high risk patients with severe disease, risk of bile duct injury does not vary between patients that underwent $\mathrm{LC}$ or $\mathrm{PC}$ (Overall rate $0.16 \%$, $\mathrm{p}$ value $0.12 \mathrm{Cl} 95 \%$ ).

Impact in the financial burden can be considered another valuable outcome usually related and measured with the in-hospital stay [16]. In our population, patients that followed PC have an increased length of hospitalization compared with the cases that underwent LC (mean : 15.43 days versus 9.97) with significant statistical relationship ( $p=0.000 \mathrm{Cl} 95 \%)$, similar to results showed by Loozen et al in their clinical trial (mean: 9 days versus 5 days $p$ value $<0.001$ ) [6].

Complications rate constitutes a corner stone when measuring and comparing any procedures. In our study the overall rate of complications was $5.95 \%$ after 30 days of follow up, similar to that described by Radunovic et al in their study that analyzed 740 patients from 2005 to 2014 who underwent LC without taking into account AC severity [17]. However, CHOCOLATE trial, shows a higher complication rate (12\%) compared with our data; and in contrast, patients that underwent PC shows a higher rate of complications of $65 \%$ in Loozen et al data [6], notwithstanding data differs in terms of lower rates in both groups, results can be considered similar due to an equal rate of complications in LC group compared to PC in patients with Tokyo III grade AC (4.24\%) with no statistical relationship between outcome and approach $(p=0.1 \mathrm{Cl} 95 \%)$.

Besides of other retrospective studies that shows an increased risk of morbidity and mortality in patients that underwent emergency LC due to acute cholecystitis (Morbidity $30-41 \%$ and mortality $5-6 \%$ ) $[8,14$, $18,19,20$ ] our data shows that in comparison with non-operative approach such as PC, surgical approach with LC could be a feasible and safe procedures with lesser rates of mortality, in-hospital stay, and requirement of re-intervention, and do not increase the risk of bile duct injury or complications, supporting the lack of data that's followed by the report of CHOCOLATE trial, and increasing the evidence in favour to surgery in high risk patients in experienced centers.

Among limitations of our study includes the retrospective nature, and the non-possibility of follow-up biliary complications, because not all the patients have re-admission in our institution. However, the sample size, and the standardized treatment with a selected interventionist radiologist, and experienced group of general surgeons in a high volume institution are included in the strengtheness of our study. 


\section{Conclusions}

Laparoscopic cholecystectomy shows lesser rate of re-intervention, mortality, and in-hospital length of stay compared with percutaneous cholecystostomy in the management of high risk patients and severe disease with acute cholecystitis. Operative approach should be considered as a safe approach although high risk or tokyo III classification, with no increased risk of complications or bile duct injury. However individualized treatment needs to be performed. Further studies are needed to prove our results.

\section{Abbreviations}

AC

Acute cholecystitis

LC

Laparoscopic cholecystectomy

PC

Percutaneous cholecystostomy

HIPAA

Health Insurance Portability and Accountability Act

ASA

American Anesthesiologist Association

ICMJE

International Committee of Medical Journal Editors

IRB

Ethics and Research Institutional Committee

IQRs

Interquartile ranges

BMI

Body mass index

\section{Declarations}

Acknowledgments: To our patients.

\section{Conflict of interest}

Dr. David Venegas has no conflicts of interest or financial ties to disclose. Dr. Carlos Rey has no conflicts of interest or financial ties to disclose. Dr. Felipe Girón has no conflicts of interest or financial ties to disclose. Dr. Lina Rodriguez has no conflicts of interest or financial ties to disclose. Dr. Marco Vanegas has no conflicts of interest or financial ties to disclose. Dr. David Peña has no conflicts of interest or financial ties to disclose. Sebastian Puello has no conflicts of interest or financial ties to disclose. Dr. Barbara Rodriguez has no conflicts of interest or financial ties to disclose. Dr. Susana Rojas has no 
conflicts of interest or financial ties to disclose. Dr. Danny Conde has no conflicts of interest or financial ties to disclose.

\section{Funding}

This research did not receive any specific grant from funding agencies in the public, commercial, or notfor-profit sectors.

\section{Ethics approval and consent to participate}

All the experimental protocols were approved by our Institutional Review Board and ethical committee (Hospital Universitario Mayor Méderi), all procedures performed in studies involving human participants were in accordance with the ethical standards of the institutional and/or national research committee, and with the 1964 Helsinki Declaration and its later amendments or comparable ethical standards. Informed consent was obtained from all individual participants included in the study.

\section{Availability of materials and data}

The datasets generated and/or analyzed during the current study are not publicly available due to institutional protocols but are available from the corresponding author on reasonable request.

\section{Consent for publication}

Not applicable

\section{Author contribution}

All authors contributed to the study's conception and design. Material preparation, data collection, and analysis were performed by DV, CR, FG, DC, and LR. The first draft of the manuscript was written by DC, FG, LR, DV, CR, DP, SP, BR, and SR, and all authors commented on previous versions of the manuscript. DC is the chief and chairman of this work. All authors read and approved the final manuscript.

\section{References}

1. Vaibhav Wadhwa Y, Jobanputra SK, Garg S, Patwardhan D, Mehta MR, Sanaka, Nationwide trends of hospital admissions for acute cholecystitis in the United States, Gastroenterology Report, Volume 5, Issue 1, February 2017, Pages 36-42, https://doi.org/10.1093/gastro/gow015.

2. Friedman GD. Natural history of asymptomatic and symptomatic gallstones. Am J Surg. 1993;165:399-404.

3. Shaffer EA. Epidemiology and risk factors for gallstone disease: has the paradigm changed in the 21st century? Curr Gastroenterol Rep. 2005;7:132-40.

4. Yokoe M, Hata J, Takada T, Strasberg SM, Asbun HJ, Wakabayashi G, Kozaka K, Endo I, Deziel DJ, Miura F, Okamoto K, Hwang TL, Huang WS, Ker CG, Chen MF, Han HS, Yoon YS, Choi IS, Yoon DS, 
Noguchi Y, Shikata S, Ukai T, Higuchi R, Gabata T, Mori Y, Iwashita Y, Hibi T, Jagannath P, Jonas E, Liau KH, Dervenis C, Gouma DJ, Cherqui D, Belli G, Garden OJ, Giménez ME, de Santibañes E, Suzuki K, Umezawa A, Supe AN, Pitt HA, Singh H, Chan ACW, Lau WY, Teoh AYB, Honda G, Sugioka A, Asai K, Gomi H, Itoi T, Kiriyama S, Yoshida M, Mayumi T, Matsumura N, Tokumura H, Kitano S, Hirata K, Inui $\mathrm{K}$, Sumiyama Y, Yamamoto M. Tokyo Guidelines 2018: diagnostic criteria and severity grading of acute cholecystitis (with videos). J Hepatobiliary Pancreat Sci. 2018 Jan;25(1):41-54.

doi:10.1002/jhbp.515. Epub 2018 Jan 9. PMID: 29032636.

5. Keus F, Gooszen HG, van Laarhoven CJ. Open, small-incision, or laparoscopic cholecystectomy for patients with symptomatic cholecystolithiasis. An overview of Cochrane Hepato-Biliary Group reviews. Cochrane Database Syst Rev 2010;(1):CD008318. [PMCID: PMC7180153] [PubMed: 20091665].

6. Loozen CS, van Santvoort HC, van Duijvendijk P, Besselink MG, Gouma DJ, Nieuwenhuijzen GA, Kelder JC, Donkervoort SC, van Geloven AA, Kruyt PM, Roos D, Kortram K, Kornmann VN, Pronk A, van der Peet DL, Crolla RM, van Ramshorst B, Bollen TL, Boerma D. Laparoscopic cholecystectomy versus percutaneous catheter drainage for acute cholecystitis in high risk patients (CHOCOLATE): multicentre randomised clinical trial. BMJ. 2018 Oct 8;363:k3965. doi: 10.1136/bmj.k3965. PMID: 30297544; PMCID: PMC6174331.

7. Fukami Y, Kurumiya Y, Mizuno K, Sekoguchi E, Kobayashi S. Cholecystectomy in octogenarians: be careful. Updates Surg. 2014;66:265-8. 10.1007/s13304-014-0267-y [PubMed: 25266894] [CrossRef: 10.1007/s13304-014-0267-y].

8. Miura F, Takada T, Strasberg SM, et al. Tokyo Guidelines Revision Comittee TG13 flowchart for the management of acute cholangitis and cholecystitis. J Hepatobiliary Pancreat Sci. 2013;20:47-54. 10.1007/s00534-012-0563-1 [PubMed: 23307003] [CrossRef: 10.1007/s00534-012-0563-1].

9. Jang WS, Lim JU, Joo KR, Cha JM, Shin HP, Joo SH. Outcome of conservative percutaneous cholecystostomy in high-risk patients with acute cholecystitis and risk factors leading to surgery. Surg Endosc. 2015;29:2359-64. 10.1007/s00464-014-3961-4 [PubMed: 25487543] [CrossRef: 10.1007/s00464-014-3961-4].

10. Sanjay P, Mittapalli D, Marioud A, White RD, Ram R, Alijani A. Clinical outcomes of a percutaneous cholecystostomy for acute cholecystitis: a multicentre analysis. HPB (Oxford). 2013;15:511-6. 10.1111/j.1477-2574.2012.00610.x [PMCID: PMC3692020] [PubMed: 23750493] [CrossRef: 10.1111/j.1477-2574.2012.00610.x].

11. Bhatt MN, Ghio M, Sadri L, Sarkar S, Kasotakis G, Narsule C, Sarkar B. Percutaneous Cholecystostomy in Acute Cholecystitis-Predictors of Recurrence and Interval Cholecystectomy. J Surg Res. 2018 Dec;232:539-546. doi: 10.1016/j.jss.2018.06.051. Epub 2018 Aug 3. PMID: 30463770.

12. Garcés-Albir, M., Martín-Gorgojo, V., Perdomo, R., Molina-Rodríguez, J. L., Muñoz-Forner,E., Dorcaratto, D., ... Sabater, L. (2019). <background-color:; i>Acute cholecystitis in elderly and high-risk surgical patients: is percutaneous cholecystostomy preferable to emergency cholecystectomy? Journal of 
Gastrointestinal Surgery, 24(11),2579-2586.</background-color:;i>doi:10.1007/s11605-019-04424-

5.

13. Winbladh A, Gullstrand P, Svanvik J, Sandström P. Systematic review of cholecystostomy as a treatment option in acute cholecystitis. HPB (Oxford). 2009;11:183-93. 10.1111/j.14772574.2009.00052.x [PMCID: PMC2697889] [PubMed: 19590646] [CrossRef: 10.1111/j.14772574.2009.00052.x].

14. Nikfarjam $M$, Yeo D, Perini $M$, et al. Outcomes of cholecystectomy for treatment of acute cholecystitis in octogenarians. ANZ J Surg. 2014;84:943-8. 10.1111/ans.12313 [PubMed: 23910372] [CrossRef: 10.1111/ans.12313].

15. Törnqvist B, Waage A, Zheng Z, Ye W, Nilsson M. Severity of Acute Cholecystitis and Risk of latrogenic Bile Duct Injury During Cholecystectomy, a Population-Based Case-Control Study. World J Surg. 2016 May;40(5):1060-7. doi: 10.1007/s00268-015-3365-1. PMID: 26669783.

16. Rice CP, Vaishnavi KB, Chao C, Jupiter D, Schaeffer AB, Jenson WR, Griffin LW, Mileski WJ. Operative complications and economic outcomes of cholecystectomy for acute cholecystitis. World $\mathrm{J}$ Gastroenterol. 2019 Dec 28;25(48):6916-6927. doi: 10.3748/wjg.v25.i48.6916. PMID: 31908395; PMCID: PMC6938729.

17. Radunovic M, Lazovic R, Popovic N, Magdelinic M, Bulajic M, Radunovic L, Vukovic M, Radunovic M. Complications of Laparoscopic Cholecystectomy: Our Experience from a Retrospective Analysis. Open Access Maced J Med Sci. 2016 Dec 15;4(4):641-646. doi: 10.3889/oamjms.2016.128. Epub 2016 Nov 9. PMID: 28028405; PMCID: PMC5175513.

18. Ambe PC, Weber SA, Christ H, Wassenberg D. Primary cholecystectomy is feasible in elderly patients with acute cholecystitis. Aging Clin Exp Res. 2015;27:921-6. doi:10.1007/s40520-015-0361-0.

19. Sanjay P, Mittapalli D, Marioud A, White RD, Ram R, Alijani A. Clinical outcomes of a percutaneous cholecystostomy for acute cholecystitis: a multicentre analysis. HPB (Oxford). 2013 Jul;15(7):511-6. doi: 10.1111/j.1477-2574.2012.00610.x. Epub 2012 Nov 19. PMID: 23750493; PMCID: PMC3692020.

20. Saeb-Parsy K, Mills A, Rang C, Reed JB, Harris AM. Emergency laparoscopic cholecystectomy in an unselected cohort: a safe and viable option in a specialist centre. Int J Surg. 2010;8(6):489-93. doi: 10.1016/j.jjsu.2010.06.015. Epub 2010 Jul 13. PMID: 20633707. 